\title{
Blackwater Fever (BWF): About a Case in the Intensive Care Unit of the Hospital University Centre Souro-Sanou in Bobo-Dioulasso, Burkina Faso
}

\author{
Barro Sie Drissa $^{1,}$, , Traore Ibrahim Alain ${ }^{1}$, Sawadogo Appolinaire ${ }^{2}$, Ki Kelan Bertille ${ }^{1}$, \\ Kamboule Bebard Euloges ${ }^{2}$, Rouamba Alexis ${ }^{1}$, Bayala Bale ${ }^{3}$ \\ ${ }^{1}$ Service of Anesthesia and Resuscitation, Departement of Surgery, Souro-Sanou University Hospital Centre of Bobo-Dioulasso, Bobo- \\ Dioulasso, Burkina Faso \\ ${ }^{2}$ Department of Medicine, Souro-Sanou University Hospital Centre of Bobo-Dioulasso, Bobo-Dioulasso, Burkina Faso \\ ${ }^{3}$ Laboratory of Animal Physiology, Training and Research Unit in Life and Earth Sciences, University of Ouagadougou, Ouagadougou, \\ Burkina Faso
}

Email address:

drissab@yahoo.fr (Barro Sie Drissa)

\section{To cite this article:}

Barro Sie Drissa, Traore Ibrahim Alain, Sawadogo Appolinaire, Ki Kelan Bertille, Kamboule Bebard Euloges, Rouamba Alexis, Bayala Bale. Blackwater Fever (BWF): About a Case in the Intensive Care Unit of the Hospital University Centre Souro-Sanou in Bobo-Dioulasso,

Burkina Faso. Journal of Diseases and Medicinal Plants. Vol. 2, No. 1, 2016, pp. 5-7. doi: 10.11648/j.jdmp.20160201.12

\begin{abstract}
Intravascular hemolysis, particularly blackwater fever is a rare but severe clinical syndrome, occurring after ingestion of antimalarials. Diagnosis relies on clinical symptoms and on the color of the urines. A resurgence of this affection which occurred frequently during the colonization has lately been noticed. We report a case of blackwater fever complicated with severe renal failure and severe acute hemolysis having evolved favorably with modest resuscitation means. A 16 year teenager from Burkina Faso, who regularly takes quinine to treat malaria presumptive access, presented the waning of an undocumented malaria, fever, consciousness disorders, anemia, jaundice and blackish urine. The thick drop, blood cultures and urine cultures were negative. Biology revealed leukocytosis $14,000 / \mathrm{mm}^{3}$, anemia in $6.5 \mathrm{~g} / \mathrm{dL}$, total bilirubin $80 \mu \mathrm{mol} / \mathrm{L}$ and kidney failure at $13 \mathrm{mmol} / \mathrm{L}$ of azotemia and $700 \mu \mathrm{mol} / \mathrm{L}$ creatinine. The evolution was favorable after a modest resuscitation. Blackwater fever still exists in our daily practice. We need to think about in front of sudden onset of hemolysis and acute renal failure with dark-red colored urine during treatment of malaria. We are facing an issue thus a rational use of antimalarials is necessary.
\end{abstract}

Keywords: Blackwater Fever, Malaria, Hemoglobinuria, Quinine

\section{Introduction}

Blackwater fever (BWF) is a severe form of malaria characterized by the occurrence of acute intravascular hemolysis immediately associated with profound anemia. The diagnosis of BWF is essentially based on clinical signs including urine color that is "dark" red appearance $[1,2,3]$. The disease was described almost exclusively among Europeans living in malaria endemic area and consuming, repeatedly and prolonged quinine for prophylaxis or curative purposes but irregularly or inadequate doses $[1,4]$. It has also been described with halofantrine and mefloquine $[5,6]$. Become outstanding since 1950 with the use of chloroquine, BWF reappeared in the late $80 \mathrm{~s}$, succeeding re-use of quinine, and has since been the subject of several publications [7, 8, 9]. Typically, BWF realizes a table associating acute intravascular hemolysis, anemia, jaundice, hemoglobinuria and usually acute kidney failure that makes all its severity [8]. The mortality rate around $23 \%$ and the morbidity is high because the majority of patients have suffered from renal failure $[10,11,12]$. We report a case of severe hemolysis and BWF with severe acute kidney failure.

\section{Observation}

A teenager girl of 16 years old was admitted the $05 / 15 / 2015$ in the intensive care unit (ICU) of the Hospital University Centre, Souro-Sanou (CHUSS) for febrile coma, jaundice and dark urine emission. 
Three days earlier, she had presented a fever at $38^{\circ} \mathrm{C}$ with chills, headache, myalgia and lumbar pain. Faced with these signs of suggestive malaria according to her mother, a health worker, she was treated by the oral quinine $(600 \mathrm{mg}$ / day for $55 \mathrm{Kg})$.

Forty-eight hours later, the fever persisted and was associated with anorexia, early postprandial food and bilious vomiting, and emission of increasingly rare red urine. Admitted to a health center, she received quinine intravenously to replace oral quinine.

In 72 hours, her condition worsened, by the occurrence of a hypotonia, a consciousness disorder, and rare blackish urine. She was transferred in the intensive care unit of CHUSS.

The questioning found no particular history. The initial examination noted an asthenic patient with $39.5^{\circ} \mathrm{C}$ of fever, a blood pressure at $100 / 60 \mathrm{mmHg}$ with a heart rate of 100 $\mathrm{b} / \mathrm{min}$, pallor, conjunctival jaundice and a Glasgow score at 13. The rest of the examination showed a dyspnea and blackish urine like Coca Cola.

The initial biological assessment found: Hemoglobin 6.5 $\mathrm{g} / \mathrm{dL}$, leukocytes $14000 / \mathrm{mm}^{3}$, platelets $100000 / \mathrm{mm}^{3}$, urea 13 $\mathrm{mmol} / \mathrm{Ll}$, creatinine $700 \mu \mathrm{mol} / \mathrm{Ll}$, total bilirubin $80 \mu \mathrm{mol} / \mathrm{L}$, conjugated bilirubin $25 \mu \mathrm{mol} / \mathrm{Ll}$, ASAT $92 \mathrm{IU} / \mathrm{L}$, ALAT 60 $\mathrm{IU} / \mathrm{L}$ and the research of Plasmodium was negative. The electrophoresis showed a hemoglobin AA phenotype. Hematuria research by the reagent strip were negative. The direct and indirect Coombs test and G6PD dosing have not been made. Blood cultures came back negative.

Before the suspicion of BWF complicated with severe kidney failure, symptomatic treatment was instituted: oxygen therapy and intravenous fluid macromolecule $(1000 \mathrm{~mL})$ and ringer lactate, associated to the transfusion of three packed red blood cells. High doses of furosemide $(800 \mathrm{mg} / 24 \mathrm{~h})$ are administered at the syringe pump to restore diuresis. Quinine was stopped and replaced with artemether through injectable route. The evolution was marked in the third day by apyrexia, hemodynamic stabilization and diuresis to $1750 \mathrm{ml} / 24 \mathrm{~h}$. Similarly, a regression of jaundice and a recovery of appetite were noted. Biologically, leukocytes were back to $9000 / \mathrm{mm}^{3}$, hemoglobin $10 \mathrm{~g} / \mathrm{dL}$, total bilirubin $50 \mu \mathrm{mol} / \mathrm{L}$. This improvement allowed to switch to the oral route with artemether and folic acid. The patient was declared cured and left the hospital 7 days post admission.

\section{Discussion}

The diagnosis of BWF is based on fever, quinine taken before the event, hemoglobinuria and anemia. The World Health Organization (WHO) defines indeed BWF as a pathological entity corresponding to severe intravascular hemolysis with a hemoglobinuria (dark-red colored urine) and profound anemia, associated with zero or low parasitaemia, occurring in a European expatriate living in endemic zone for several years and dealing improperly with quinine [13]. This definition poses problem on the ground on which it occurs and of the role of quinine in the BWF.
Indeed, the mechanism governing the occurrence of Blackwater fever remains unexplained. Some authors blame quinine and raise the possibility of an immune reaction against erythrocytes sensitized by a previous century of taken quinine [1, 14]. However, other antimalarials such as mefloquine and halofantrine were cited as factors causing the disease; in addition, it is increasingly described among African and Asian populations [7, 8, 9, 15]. The clinical presentation is stereotyped, occurring during the 24 to 48 hours after administration of antimalarial drugs such as quinine, halofantrine, mefloquine [7]. It is manifested by the sudden onset of dark-red colored urine, jaundice, paleness, nausea and acute renal failure. Anemia is immediately severe. Other symptoms can be observed such as abdominal pain, vomiting, hepatosplenomegaly, dyspnea, tachycardia, general malaise and vertigo. The clinical picture can also be asymptomatic [16, 17]. Renal involvement is secondary to acute tubular necrosis. Parasitaemia is absent or low [1]. Dark-red colored urine is the most constant sign. Bodi et al. (2013) in Democratic Republic of Congo (DRC) found that aspect of urine in all patients [18]. Our observation is distinguished by the appearance of BWF after taking quinine in a patient living in malaria-endemic area. In DRC, Bodi et al. (2013) reported in a series of 43 cases of BWF that the majority (95\%) are secondary to the use of quinine [18]. In our case, clinical and biological arguments show the disease. Indeed, the negativity of the research of Plasmodium by smear doesn't eliminate the check; this fact is current during the BWF $[4,8,9]$. For WHO, biological criteria of poor prognosis are the leukocytosis greater than $12,000 / \mathrm{mm}^{3}$, hemoglobin levels below $7.1 \mathrm{~g} / \mathrm{dL}$ and creatininemia greater than $65 \mu \mathrm{mol} / \mathrm{L}$ [6]. In some series, kidney failure during the disease sometimes needs dialysis [4, 9]. For many authors, despite the initial severity of the BWF, the cure is achieved these days without damage by replacing the offending molecule of quinine by artemether associated with adequate resuscitation $[4,9,15]$.

\section{Conclusion}

In conclusion, the $\mathrm{BWF}$ is a re-emerging disease, responsible for an array of kidney failures and acute hemolysis requiring nephrology and hemodynamic intensive care to achieve a rapid healing without damage. It is secondary to the use of quinine in the treatment of Plasmodium falciparum malaria. We need to think about BWF in front of sudden onset of hemolysis with acute renal failure and dark-red colored urine during treatment of malaria. In Burkina Faso, the respect of Ministry of Health guidelines, that promote the prescription of combined treatments associated with a reduction in the self-medication, will reduce and better manage cases of $\mathrm{BWH}$.

\section{References}

[1] F Bruneel, B Gachot, M Wolff, JP Bedos, B Regnier, M Damis, F Vachon. Blackwater fever. Presse Med. 2002; 31 (28): $1329-34$. 
[2] A Thiongane, AA Ndongo, PM Faye, A Sylla' Y Kéita, D Boiro, I Basse, NR Diagne-Guèye, O Ndiaye. Blackwater fever of late apparition: about one case in CHU of Dakar. The Pan African Medical Journal. 2015; 22: 301.

[3] AA Oumar, B Poudiougou, M Sylla, A Sall, S Konate, B Togo, M Diakite, MM Keita. Blackwater fever in children during cerebral malaria: 3 case-report in Bamako. Pediatr Arch. 2007; 14(8): 993-5.

[4] F Bruneel, B Gachot, M Wolff, B Regnier, M Danis, F Vachon. Resurgence of black water fever in long-term European expatriates in Africa: report of 21 cases and review. Clin Infect Dis. 2001; 32(8): 1133-40.

[5] M Danis, JP Nozais, L Paris, C Robert, C Katlama, M Gentilini, C Raynaud de Lage. Blackwater fever after taking mefloquine. Three observations. Presse Med 1993; 22 (2): 80.

[6] C Delacollette, L Isabella, C Atzori, A Cargnel. Blackwater fever after-halofantrine. Lancet 1996; 347: 1408-1409.

[7] MA Bouldouyre, D Dia, T Carmoi, K Ba Fall, B Chevalier, JM Debonne. A Blackwater fever of medium gravity. Med Mal Infect. 2006; 36(6): 343-345.

[8] A Djibo A-Sunna Adamou, S Brah Bouzou. Blackwater fever in adults with sickle cell disease about two deaths. Med Trop 2000; 60: 156-158.

[9] EWC Nacoulma, H Tieno, R Traoré, C Ouédraogo, A Lengani, J Drabo. Blackwater fever of the service in the internal medicine Centre Hospitaler National Yalgado Ouédraogo of Ouagadougou. Med Afr Noire. 2004; 51: 575578.

[10] LE Assi, Y Brouh, J Sissokho, AA Amonkou, B Vilasco, A Gnionsahe, DS Coffi. Blackwater fever: clinical, paraclinical, therapeutic and evolving aspects: about 13 cases in Abidjan. Med Afr Noire. 1999; 46(10): 451-3.
[11] TH Daubrey-Potey, H Die-Kacou, M Kamagate, M Vamy, E Balayssac, JC Yavo. Blackwater fever during antimalarial treatment in Abidjan: 41 cases report. Bull Soc Pathol Exot. 2004; 97(5): 325-8.

[12] C Lon, M Spring, S Sok, S Chann, R Bun, M Ittiverakul, N Buathong, K Thay, N Kong, Y You, W Kuntawunginn, C A Lanteri, D L Saunders. Blackwater fever in an uncomplicated Plasmodium falciparum patient treated with dihydroartemisinin-piperaquine. Malar J. 2014; 13(1): 96-9.

[13] World Health Organization. Severe and complicated malaria. Trans R Soc Trop Med Hyg 1990; 84 (suppl. 2): 1-64.

[14] O Lesieur, P Dudeffant, B Courtriade, P Haglund. Blackwater fever: a fatal case. Intensive Care Med 1997; 23: 1188.

[15] TH Tran, NP Day, LV Chuong, NTH Mai, PP Loc, NH Phu, DB Bethell, DX Sinh, TT Hien, NJ White. Blackwater fever in southern Vietnam: a prospective descriptive study of 50 cases. Clin Infect Dis 1996; 23: 1274-1278.

[16] F Gobbi, S Audagnotto, L Trentini, I Nkurunziza, M Corachan, G Di Perri. Blackwater fever in children, Burundi. Emerg Infect Dis. 2005; 11(7): 1118-20.

[17] A O'Donnell, DJ Weatherall, AM Taylor, JC Reeder, SJ Allen. Muscle cell injury, haemolysis and dark urine children with falciparum malaria in Papua New Guinea. Trans R Soc Trop Med Hyg. 2006, 100(9): 817-25.

[18] JM Bodi, CN Nsibu, RL Longenge, MN Aloni, PZ Akilimali, PM Tshibassu, PK Kayembe, A H Omar, K Hirayama, J Verhaegen. Blackwater fever in Congolese children: a report of clinical, laboratory features and risk factors. Malar J. 2013; 12(1): 205-10. 